\title{
Study of the composition of innovative materials for the restoration and strengthening of machine parts
}

\author{
Andrei Gorin ${ }^{1, *}$, Ivan Kuznetsov ${ }^{2}$, Tatiana Prokoshina ${ }^{2}$, Elena Byrlakova ${ }^{1}$, and Svetlana \\ Kolpakova ${ }^{1}$ \\ ${ }^{1}$ Orel State University named after I.S.Turgenev, Komsomolskaya st. 95, 302026, Orel, Russia \\ ${ }^{2}$ Orel State Agrarian University named after N.V. Parakhin, Orel, Russia
}

\begin{abstract}
The article describes promising, innovative materials for the restoration of machine parts. The elemental composition was studied by atomic emission spectrometry with inductively coupled plasma. The elemental composition of amorphous alloys of grades 84KHSR, 2HSR, $82 \mathrm{H} 7 \mathrm{HSR}$ and nanocrystalline alloy of grade 5BDSR was studied. Based on the results of elemental analysis, it can be argued that the chemical composition of the materials studied by us will help to increase the productivity of technological processes of recovery and the formation of amorphous or nanocrystalline structures of high microhardness in the reducing coatings
\end{abstract}

\section{Introduction and Problem formulation}

The main factor that determines the effectiveness of the process of restoring parts is the choice of the applied material. The material must have sufficient hardness, strength, and optimal thermal properties for the friction pair. Amorphous and nanocrystalline alloys often have such mutually exclusive properties [1-5]. With their help, it is possible to obtain strengthening coatings with amorphous or nanocrystalline structures that have high physical and mechanical properties and wear resistance [6-8].

One of the reasons that hinders the widespread use of amorphous and nanocrystal structures in the restoration and strengthening of machine parts is that under thermal influence or insufficient cooling rate, the cluster clusters that form their basis evolve to nanocrystals and microcrystals that have a pronounced crystallographic symmetry group. This evolution strongly changes the physical and mechanical properties of materials $[2,3,4]$. After analyzing the works [1-5], it can be argued that the scale of evolution of cluster clusters into nanocrystals and microcrystals depends mainly on the chemical composition of materials. Therefore, when using amorphous and nanocrystal structures as reducing materials, it is necessary to simultaneously study and control the chemical composition of alloys.

\footnotetext{
*Corresponding author: gorin57@mail.ru
} 


\section{Theoretical part}

Amorphous structures and nanocrystal structures are completely new alloys. Their structure implies the absence of such defects as dislocation, liquation, and segregation, which are characteristic of alloys with a bulk microcrystalline structure. The amorphous structure is the most disordered of all solids. However, from a chemical point of view, it is close to homogeneous. The mechanical and thermal characteristics of amorphous and nanocrystal structures vary significantly depending on the elemental composition. Therefore, knowledge of the chemical composition of reducing materials is one of the necessary conditions for predicting the quality parameters of reducing coatings. At present, there are not enough experimental works that would confirm each other and determine the exact elemental composition of the alloys proposed by us for recovery.

One of the most common methods for multi-element analysis of objects of various nature is currently atomic emission spectrometry with inductively coupled plasma. In this regard, the elemental composition of as brands 84KHSR, 2NSR, 82N7HSR and nanocrystal structures brand 5BDSR, offered by us as materials for the restoration of machine parts, was determined by this method.

\section{Experimental studies}

An atomic emission spectrometer with inductively coupled plasma of the ICAP-6300 Duo brand produced by Thermo Scientific (Fig. 1) was used as a measurement tool. the spectrometer was equipped with a peristaltic pump for entering solutions into the spectrometer. The studies were performed with the following parameters of the spectrometer: generator output power $1150 \mathrm{~W}$; argon pressure in the purge line $0.65 \mathrm{MPa}$; plasma-forming argon flow $12 \mathrm{l} / \mathrm{min}$; auxiliary argon flow $0.5 \mathrm{l} / \mathrm{min}$; spray argon flow $0.7 \mathrm{l} / \mathrm{min}$; plasma generator frequency $27.12 \mathrm{MHz}$; measurement time $30 \mathrm{~s}$; the speed of the peristaltic pump is $50 \mathrm{~min}^{-1}$; the registration time is 10 seconds.

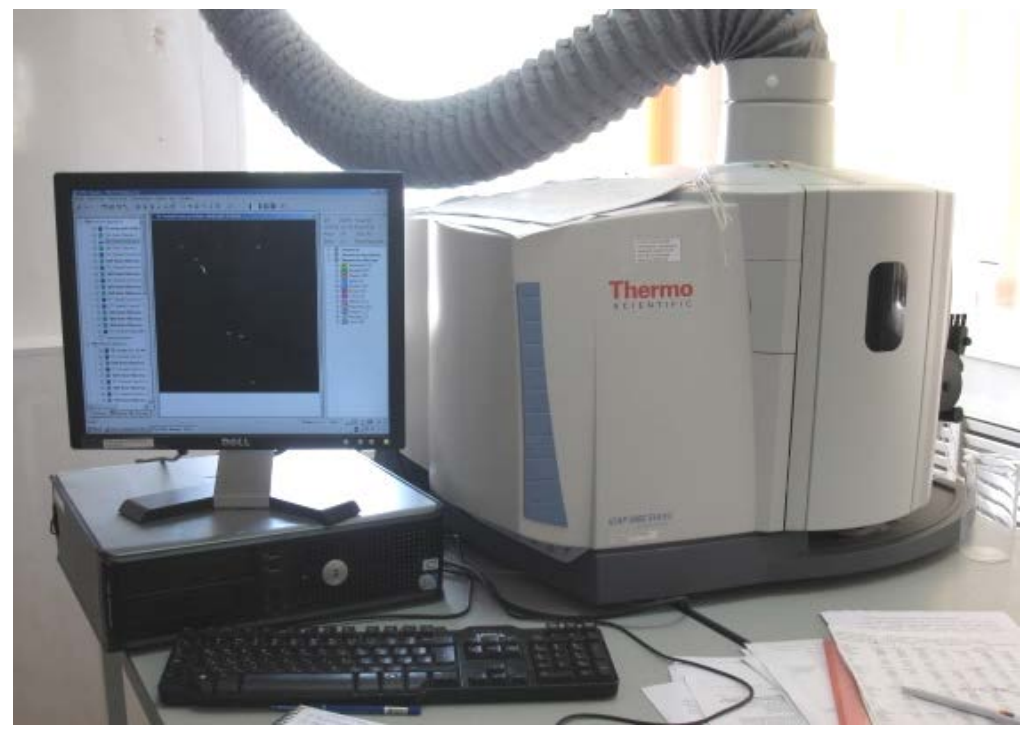

Fig. 1. General view of the emission spectrometer ICAP 6300

Samples for research were cut from quick-quenched tapes in the form of rectangular plates $10 \times 10 \mathrm{~mm}$ in size. Primary cleaning of the samples was performed with a powder mixture of sodium bicarbonate until visible contamination was removed. The remnants of 
the sodium bicarbonate was removed by rinsing with distilled water followed by washing in redistillate. Immediately before etching, the samples were washed with ethyl alcohol-a rectifier. Then it was dried in a CONTERM drying Cabinet at a temperature of $105^{\circ} \mathrm{C}$, cooled in a desiccator for 20 minutes and weighed. Weighing was performed on analytical scales of the Sartorius Competence CP 64 brand. Etching was performed in a mixture of hydrochloric acid GOST 3110 and nitric acid GOST 4461, in a ratio of three to one, respectively. Forty milliliters of the initial solution was poured into a glass narrow-necked conical flat-bottomed flask with a capacity of $250 \mathrm{ml}$ and the sample was immersed in it (Fig. 2).

Etching was performed in the BETA PB autoclave system at a temperature of $105^{\circ} \mathrm{C}$ and with an excess pressure of 0.1 bar until the visible sample residue disappeared.

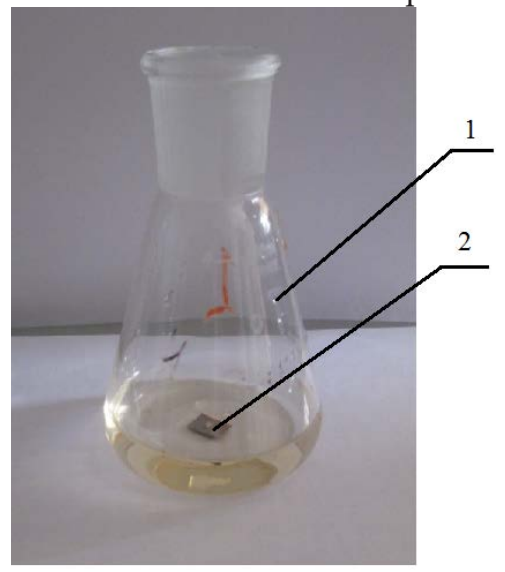

Fig. 2. Preparation of samples for the spectrometer: 1-flask; 2-sample for research

Bidistilled water was added to the resulting solution until a total volume of $100 \mathrm{ml}$ was obtained. The resulting solution was placed in a chamber with a spectrum excitation source by means of a peristaltic pump and a $4 \mathrm{~mm}$ diameter teflon tube.

\section{Results}

Using the method of atomic emission spectrometry with inductively coupled plasma, a qualitative (Fig. 3) and quantitative elemental analysis of amorphous and nanocrystal structures used to obtain reducing coatings was performed. More than 30 chemical elements were identified in the composition of materials used for recovery. From the obtained set of analytical spectral lines, we selected one line for each chemical element. The choice was made based on the condition of minimum values of spectral interference. Chemical elements whose content in the alloys was more than $0.1 \%$ (Table 1$).$. The content of such chemical elements as Al, Cd, P, Bi, Ti, Sb, Sr, Zr, Hf, Ta, and Re in the studied alloys was less than $0.1 \%$, so they are not presented in table 1 . It was found that the studied materials have a large number of different impurities that can significantly affect the quality indicators of the studied reducing coatings.

In [2 6], the authors state that the microhardness of the amorphous structures increases mainly as a result of filling the metalloid atoms with electrons, the valence levels of the atoms of the main metal component of transition metals. Based on this and the results of our own elemental analysis, we can assume that the presence of a relatively large number of metalloid atoms in the proposed amorphous and nanocrystal structures will ensure high microhardness of the resulting reducing coatings, which will be determined mainly by the presence of $\mathrm{Si}$ and $\mathrm{B}$ in them. 

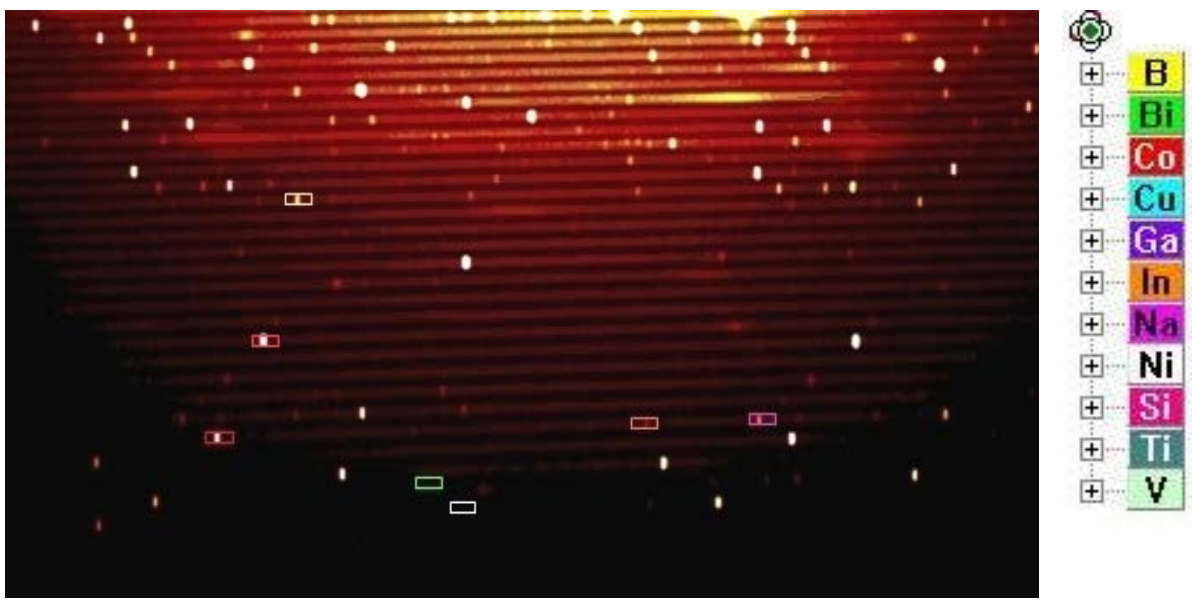

Fig. 3. Qualitative nuclear analysis of the 84 KHSR alloy

Table 1. The content of chemical elements in the alloys, $\%$

\begin{tabular}{|l|l|l|l|l|}
\hline \multirow{2}{*}{$\begin{array}{c}\text { Chemical element } \\
\text { (element wavelength) }\end{array}$} & \multicolumn{4}{c|}{ Alloy grade } \\
\cline { 2 - 5 } & $\mathbf{8 4 K H S R}$ & 5BDSR & 2NSR & 8NH7HCR \\
\hline $\mathrm{Ca}(422,6)$ & 1,13 & 1,3 & 1,5 & 1,1 \\
\hline $\mathrm{Cr}(284,3)$ & 3,24 & 0,2 & 0,22 & 4,4 \\
\hline $\mathrm{Fe}(259,9)$ & 2,88 & 70,1 & 71,3 & 2,24 \\
\hline $\mathrm{K}(769,8)$ & 0,52 & 0,86 & 0,46 & 0,29 \\
\hline $\mathrm{Li}(460,2)$ & 0,25 & 0,82 & 1,0 & 0,25 \\
\hline $\mathrm{Mg}(285,2)$ & 4,88 & 7,6 & 3,7 & 2,27 \\
\hline $\mathrm{Mn}(260,5)$ & 0,1 & 0,1 & 0,1 & - \\
\hline $\mathrm{Na}(818,3)$ & 1,65 & 0,2 & 1,5 & 0,11 \\
\hline $\mathrm{Zn}(213,8)$ & 0,15 & 0,9 & 0,3 & 0,71 \\
\hline $\mathrm{B}(249,7)$ & 8,18 & 5,46 & 9,2 & 2,81 \\
\hline $\mathrm{Co}(228,6)$ & 64,02 & - & - & - \\
\hline $\mathrm{In}(230,6)$ & 0,46 & - & - & 0,1 \\
\hline $\mathrm{Ni}(221,6)$ & 0,38 & - & 2,2 & 67,8 \\
\hline $\mathrm{Ag}(243,7)$ & - & - & 1,2 & 10,95 \\
\hline $\mathrm{Pb}(216,9)$ & - & - & 0,15 & 0,95 \\
\hline $\mathrm{Si}(251,6)$ & 11,5 & 7,2 & 6,3 & 4,35 \\
\hline $\mathrm{Cu}(324,7)$ & - & 0,8 & - & - \\
\hline $\mathrm{Mo}(204,5)$ & - & 0,2 & - & - \\
\hline $\mathrm{Nb}(309,4)$ & - & 2,21 & - & - \\
\hline $\mathrm{W}(224,8)$ & 0,48 & - & - & - \\
\hline & & & & \\
\hline
\end{tabular}

Studies of amorphous and nanocrystalline structures show that the presence of elements in alloys with a lower number of external electrons than the main metal component will also lead to an increase in hardness. This allows us to state that the presence of elements such as $\mathrm{Cr}, \mathrm{Li}, \mathrm{Mg}, \mathrm{Na}$, and $\mathrm{W}$ in the amorphous and nanocrystalline structures used by us will also favorably affect the microhardness of most of the applied reducing coatings.

The formation of the structure in reducing coatings will be determined by the presence of chemical elements in the materials of amorphizers and $\mathrm{Nb}, \mathrm{Cu}$. Thus, the presence of si atoms in the 5BDSR alloy will lead to the formation of clusters, which are the nucleation 
sites of primary $\alpha-\mathrm{Fe}(\mathrm{Si})$ crystals. The presence of $\mathrm{Nb}$ and $\mathrm{Zr}$ atoms in the 5BDSR nanocrystalline structures that slow down diffusion will help to reduce the rate of crystal growth in reducing coatings. The $\mathrm{Nb}$ and $\mathrm{B}$ atoms repelled from the cluster will contribute to the formation of stable local-order regions in its vicinity, and thus stop the growth of the $\alpha-\mathrm{Fe}(\mathrm{Si})$ crystal [7-9]. Thus, the presence of these elements in the reducing coatings will increase the dispersion and compensate for the action of $\mathrm{Cu}$ atoms. In addition, the presence of $\mathrm{Nb}$ and $\mathrm{Zr}$ in the studied materials will favorably affect the thermal stability of the reducing coatings.

\section{Conclusions}

As a result of the research, we obtained:

- the presence of $\mathrm{Mg}$ and $\mathrm{Mn}$ atoms in the studied materials will ensure a low melting point; - the chemical composition of the studied materials will help to increase the productivity of technological processes of recovery and the formation of amorphous or nanocrystalline structures of high microhardness in the reducing coatings.

\section{References}

1. S. Cadney, M. Brochu Formation of amorphous Zr41.2Ti13.8Ni10Cu12.5Be22.5 coatings via the electrospark deposition process. Intermetallics..Vol. 16. No 4. (2008)

2. M. Brochu, D. Heard, J. Milligan, S. Cadney Bulk nanostructure and amorphous metallic components using the electrospark welding process. Assembly automation.. Vol. 30. No 3. (2010)

3. J. Milligan, D. Heard, M. Brochu Formation of nanostructured weldments in the Al-Si system using electrospark welding. Applied surface science.. Vol. 256. No 12. (2010)

4. S. Cadney, G. Goodall, G. Kim, A. Moran, M. Brochu The transformation of an albased crystalline electrode material to an amorphous deposit via the electrospark welding process. Journal of alloys and compounds.. Vol. 476. No 1-2. (2009)

5. A.V. Kolomeichenko, I.S. Kuznetsov, I.N. Kravchenko Investigation of the thickness and microhardness of electrospark coatings of amorphous and nanocrystalline alloys. Welding International.. Vol. 29. No 10. (2015)

6. A.V. Kolomeichenko, I.S. Kuznetsov Tribotechnical properties the electrospark coating of amorphous and nanocrystalline alloys based on iron. Friction and wear.. Vol. 35. No 6. (2014)

7. I.S. Kuznetsov, A.V. Kolomeichenko Mass transfer of a nanocrystalline 5bdsr alloy during low-voltage electrospark treatment. Russian metallurgy (Metally). Vol. 2019. No 13. (2019)

8. A.V. Kolomeichenko, I.S. Kuznetsov, A.Y. Izmaylov, R.Y. Solovyev, S.N. Sharifullin Investigation of finemet nanocrystalline alloy coating obtained by the electric spark method. International Journal of Nanotechnology.. Vol. 15. No 4-5. (2018)

9. I.S. Kuznetsov, A.V. Kolomeichenko, V.Z. Pavlov Process of mass transfer of amorphous alloys under low-voltage electric spark treatment. Surface Engineering and Applied Electrochemistry.. Vol. 53. No 4. (2017) 